\title{
Effects of Heat Treatment on Mechanical Properties and Microstructure Evolutions of Ti-5321 Alloy
}

\author{
Jingzhe $\mathrm{Niu}^{\mathrm{a}, *}$, Yulei $\mathrm{Gu}^{\mathrm{b}}$, Yanhua Guo ${ }^{\mathrm{b},{ }^{*}}$, Wenjun $\mathrm{Wu}^{\mathrm{c}}$, Cong Wu${ }^{\mathrm{a}}$, Shewei Xin ${ }^{\mathrm{c}}$, Hui Chang ${ }^{\mathrm{b}}$, Lian Zhou ${ }^{\mathrm{a}, \mathrm{b}, \mathrm{c}}$ \\ a. State Key Laboratory for Mechanical Behavior of Materials, Xi'an Jiaotong University, Xi'an, China
}

b. College of Materials Science and Engineering and Tech Institute for Advanced Materials, Nanjing Tech University, Nanjing, China

c. Northwest Institute for Non-ferrous Metal Research, Xi'an, China

*jingzhe.niu@stu.xjtu.edu.cn / njzhe91@gmail.com

*guoyanhua@njtech.edu.cn

\begin{abstract}
This work presents a comprehensive study on the microstructure evolution and mechanical property under different heat treatment procedures of a new near $\beta$ type titanium Ti-5321(Ti-5Al-3Mo-3V-2Cr-2Zr-1Nb-1Fe). Two solution temperatures $\left(830^{\circ} \mathrm{C}\right.$ and $\left.900^{\circ} \mathrm{C}\right)$ and a group of aging temperatures $\left(300-650^{\circ} \mathrm{C}\right)$ were carried out to investigate the influence of heat treatment on this new alloy. The strengthening mechanism of Ti-5321 after solution and aging treatment was discussed by analyzing the microstructure and its mechanical properties. The best ultimate tensile strength can be achieved to $1564 \mathrm{MPa}$ with $5 \%$ on elongation when solution treated at $830^{\circ} \mathrm{C}$ and aging at $450^{\circ} \mathrm{C}$ for this new alloy. The lamellar and globular a grains can be found in all $830^{\circ} \mathrm{C}$ solution treated specimens which contribute to a better ductility. Ultra-fine a phase can be found in all low aging temperature treated specimens but will coarsen significantly when raising the aging temperature and thus increase the tensile strength and lower the ductility. All these results can provide a comprehensive guidance on heat treatment for this new near $\beta$ type titanium in the future.
\end{abstract}

\section{Introduction}

Titanium and its alloy are widely used in medical, marine and aerospace industries due to their excellent properties such as low density, high strength and good corrosion resistance. Although hundreds of titanium alloys have been developed during the past 60 years, the Ti-6Al-4V with tensile stress no more than $1200 \mathrm{MPa}$, is still the most produced titanium alloy and sharing $80 \%$ of the world market nowadays[1]. With the development of higher speed jets and stronger power engines, the strength and toughness tolerance of titanium raw materials are becoming stricter. Old designed titanium alloy such as Ti-6Al-4V cannot satisfy all needs for today's aerospace industry anymore. Because the complex phase transformations and microstructure development of near $\beta$ type titanium alloys can contribute to a better balance between strength and fracture toughness, dozens of near $\beta$ type titanium such as Ti-10V-2Fe-3Al (Ti-1023), Ti-5.5Al-5V-5Mo-1.5Cr-1Fe (BT22), Ti-5Al-5Mo-5V-3Cr (Ti5553) and Ti-5Al-5Mo-5V$3 \mathrm{Cr}-1 \mathrm{Zr}$ (Ti-55531)[2-5] have been designed during the past decades. These alloys can be categorized to two groups which are higher strength $(<1300 \mathrm{MPa})$ with lower toughness tolerance $\left(<55 \mathrm{MPa} \cdot \mathrm{m}^{1 / 2}\right)$ alloys and lower strength ( $\left.<1100 \mathrm{MPa}\right)$ with higher toughness tolerance $\left(<70 \mathrm{MPa} \cdot \mathrm{m}^{1 / 2}\right)$ alloys. While, it is hard for these titanium alloys' strength to reach $1200 \mathrm{MPa}$ with toughness tolerance over $65 \mathrm{MPa} \cdot \mathrm{m}^{1 / 2}$ simultaneously. Therefore, a new near $\beta$ type titanium Ti-5321 (Ti-5Al-3Mo-3V-2Cr-2Zr-1Nb$1 \mathrm{Fe}$ ) was designed and our previous work indicated that this alloy has an excellent balance between strength and toughness in several conditions[6, 7].

Alloy's microstructure has a huge effect on its mechanical properties. Heat treatment is one of the most important approaches to change and control titanium alloys microstructure, especially for $\beta$ or near $\beta$ type titanium alloys. In this study, two solution temperatures which are below $\left(830^{\circ} \mathrm{C}\right)$ and above $\left(900^{\circ} \mathrm{C}\right)$ phase transus temperature $\left(860^{\circ} \mathrm{C}\right)$ are involved, a group of aging temperatures $\left(300 \sim 650^{\circ} \mathrm{C}\right)$ were carried out to study the relationship between microstructure and mechanical property of this new alloy.

\section{Materials and Experimental Procedure}

2.1 Materials Preparation

The Ti-5321 alloy used in this study was fabricated through vacuum consumable arc melting, casting, forging and hot rolling and provided by Northwest Institute for Nonferrous Metal Research in China. Table 1 shows chemical composition of the alloy.

Table 1. Chemical composition of the Ti-5321 alloy[7]

\begin{tabular}{|ccccccccccccc}
\hline Element & $\mathrm{Ti}$ & $\mathrm{Al}$ & $\mathrm{Mo}$ & $\mathrm{V}$ & $\mathrm{Cr}$ & $\mathrm{Zr}$ & $\mathrm{Nb}$ & $\mathrm{Fe}$ & $\mathrm{N}$ & $\mathrm{H}$ & $\mathrm{O}$ & \\
\hline $\mathrm{wt} \%$ & Bal. & 5.02 & 3.03 & 2.99 & 2.06 & 2.01 & 1.37 & 0.99 & 0.004 & 0.0011 & 0.064 \\
\hline
\end{tabular}

Fig. 1 and Fig. 2 show the XRD pattern and microstructure of original rod before heat treatment respectively. Both $\alpha$ and $\beta$ phase can be found in the original rod. All specimens were cut to rod with $100 \mathrm{~mm}$ in length and $20 \mathrm{~mm}$ in diameter for different heat treatment. The detected phase transus temperature of Ti- 5321 alloy is $860^{\circ} \mathrm{C}$ based on previous study[6]. The specimens were grouped by two different solution temperatures which are below and above the phase transus temperature. The first group specimens were solution treated at $830^{\circ} \mathrm{C}\left(\alpha / \beta\right.$ solution) for $1.5 \mathrm{~h}$. The second group specimens were solution treated at $900^{\circ} \mathrm{C}(\beta$ solution) for $0.5 \mathrm{~h}$. All specimens were cooled in air and followed with a group of different aging temperatures. The aging process was carried out at $300^{\circ} \mathrm{C}, 400^{\circ} \mathrm{C}, 450^{\circ} \mathrm{C}, 500^{\circ} \mathrm{C}, 550^{\circ} \mathrm{C}, 600^{\circ} \mathrm{C}$ and $650^{\circ} \mathrm{C}$ for 8 hours and cooled in air. 


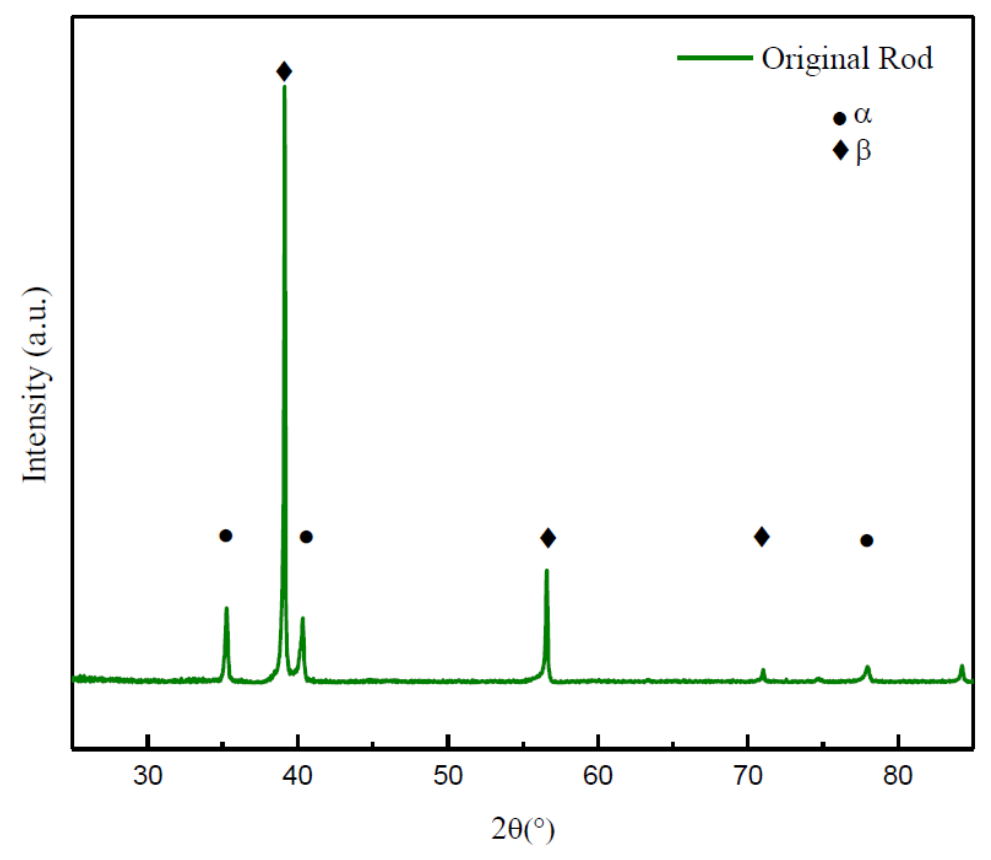

Fig 1. XRD pattern of Ti-5321 original rod

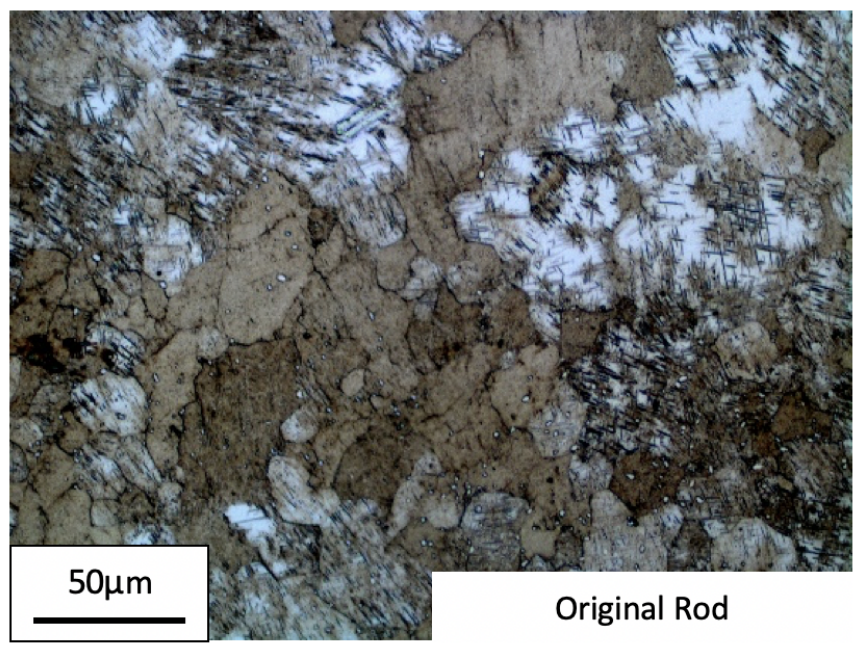

Fig 2. Microstructure of original rod specimen

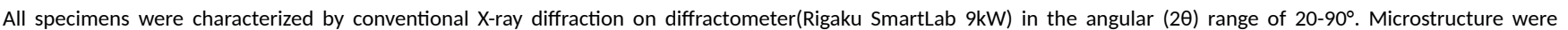
analyzed by optical microscopy (Zeiss AxioObserver A1m OM) and transmission electron microscopy (FEI TECNAI G20). Bright-field image was used to analysis the size of microstructure and electron diffraction pattern was used to identify the phases.

2.3 Mechanical property testing

Columned tensile specimens with gauge length of $25 \mathrm{~mm}$ and a cross section diameter of $5 \mathrm{~mm}$ were prepared by turning machine and polished with grinding wheel to accurate diameter. An universal testing system (INSTRON 5985) equipped with extensometer was used to record the stress-strain data at room temperature. All tensile test was performed under GB/T228.1-2010 standard. Three specimens were used for each test to ensure repeatability and the average value was considered for further analysis.

\section{Results and Discussions}

3.1 Microstructure

Fig. 3 shows the XRD pattern of Ti-5321 alloy which is treated at two different solution temperatures and aged at $300^{\circ} \mathrm{C}$. The results indicate that the phase composition of Ti- 5321 is sensitive to the solution temperature. For low aging temperature, $300^{\circ} \mathrm{C}$ in this case, two phase patterns can be found for specimens treated at $830^{\circ} \mathrm{C}(\mathrm{a} / \beta$ phase temperature) while only $\beta$ phase can be found when treated at $900^{\circ} \mathrm{C}(\beta$ phase temperature). Fig. 4 shows the microstructure of solution treated Ti-5321 under different 
solution temperatures. As can be seen in Fig. $4 \mathrm{a}$ and Fig. $4 \mathrm{~b}$, the primary a phase can only be found in $\alpha / \beta$ solution treated specimens. Fig. $4 \mathrm{c}$ and Fig. $4 \mathrm{~d}$ are showing the TEM image of different solution treated specimens. The lamellar and globular $a$ grains (identified as primary a phase) can be found in all $\alpha / \beta$ solution treated specimens with average width or diameter around 1 to $2 \mu \mathrm{m}$. Finer acicular a phase (identified as secondary a phase) can be found on $\beta$ matrix. It is well known that the primary a phase can contribute as a stumbling block on the growth of $\beta$ grains which limits the $\beta$ grains sizes and mobility significantly. By measuring the grains size shown in Fig. $4 a$ and Fig. $4 \mathrm{~b}$, the average $\beta$ grain size of $\alpha / \beta$ solution treated specimens is around $5 \mu \mathrm{m}$ while the $\beta$ grain size can be over $50 \mu \mathrm{m}$ when solution treated at $\beta$ solution temperature. The precipitation kinetics is quite slow for $\beta$ or near $\beta$ type titanium and it is fast enough to keep considerable amount of $\beta$ grains in the matrix when air cooling from high temperature near phase transus temperature[8]. It is worth to point out that the grains boundaries of $\beta$ solution treated specimens are straight which indicates the complementary of recrystallization of the deformed grains in this study[9].

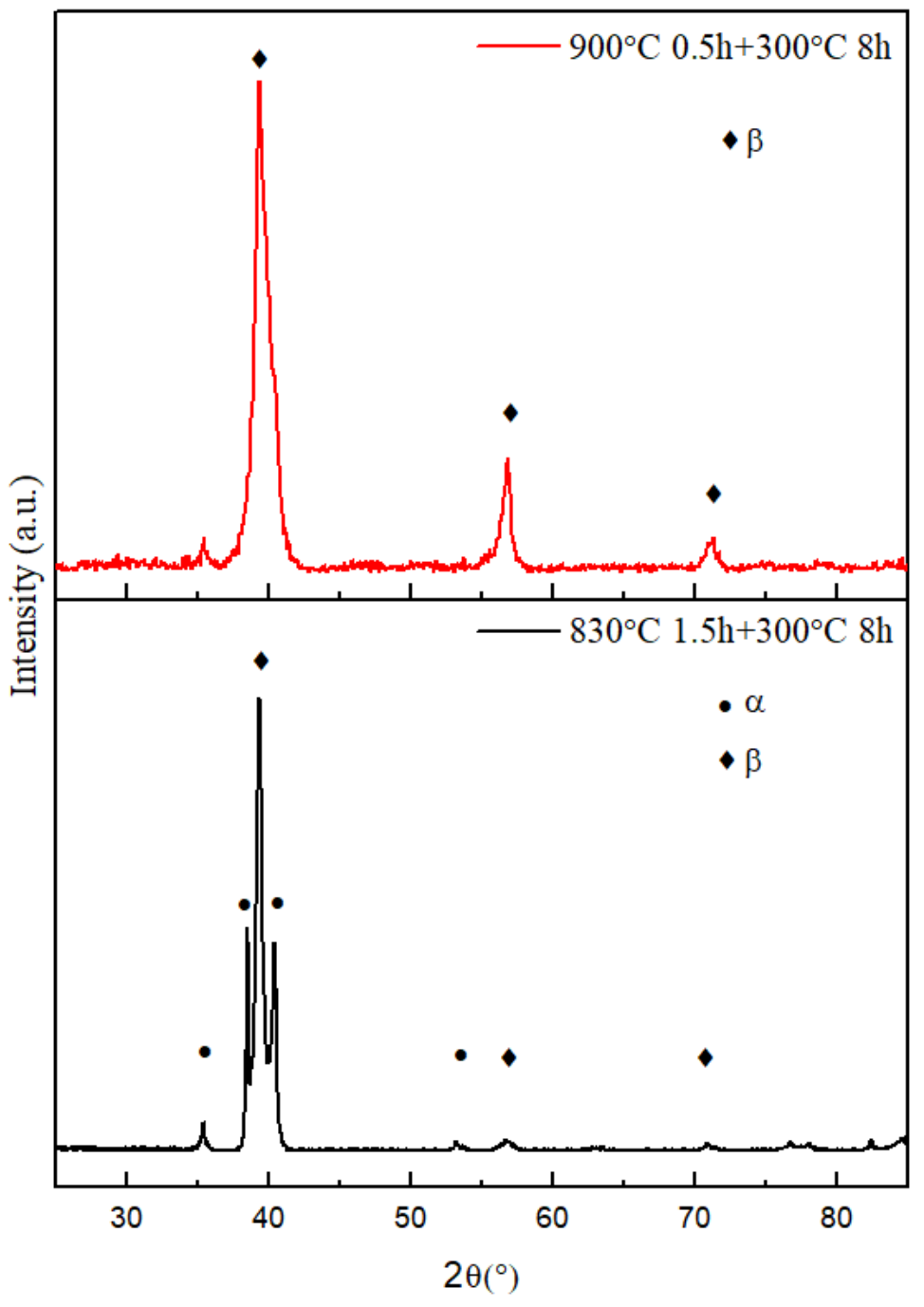

Fig 3. XRD pattern of Ti-5321 alloy under different solution temperature

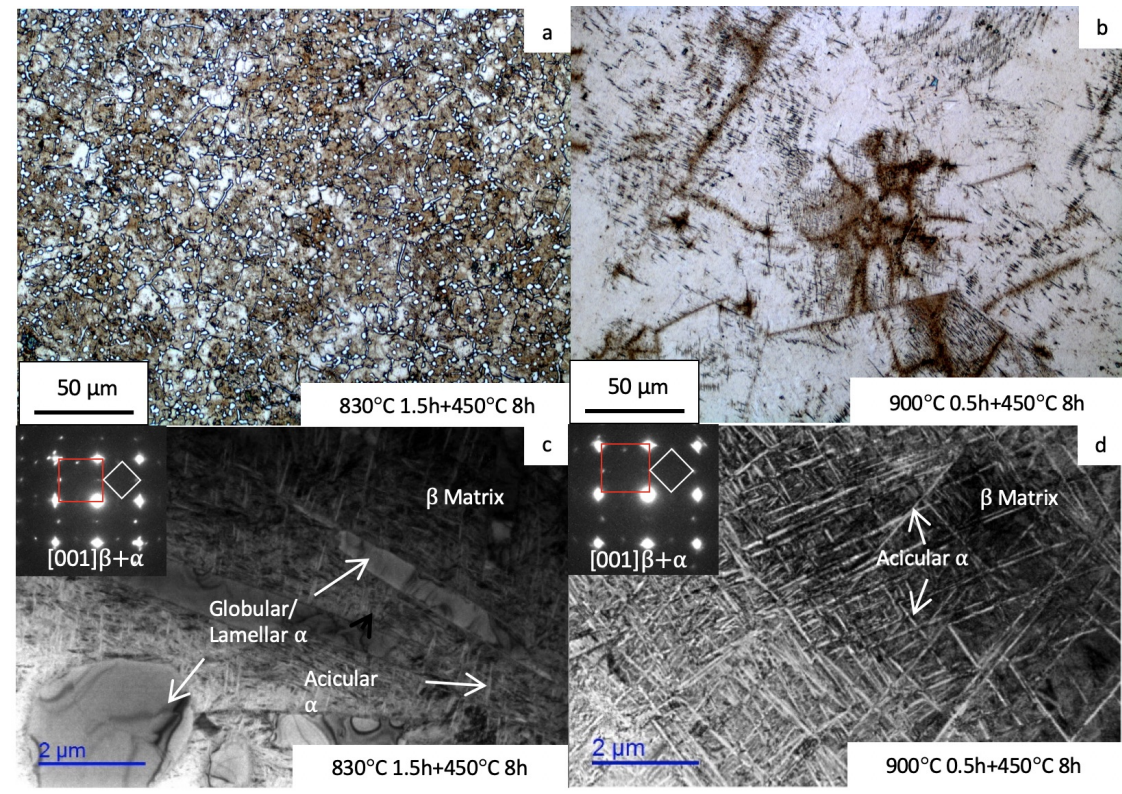


Fig 4. Microstructure of solution and aging treated Ti-5321 alloy OM(a, b) and TEM(c, d) image: a, c) $\left.830^{\circ} \mathrm{C} 1.5 \mathrm{~h}+450^{\circ} \mathrm{C} 8 \mathrm{~h}, \mathrm{~b}, \mathrm{~d}\right) 900^{\circ} \mathrm{C} 0.5 \mathrm{~h}+450^{\circ} \mathrm{C} 8 \mathrm{~h}$

Fig. 5 shows the XRD pattern of Ti- 5321 alloy after different aging treatments. Fig. 5 a shows the $830^{\circ} \mathrm{C}$ solution treated specimens and Fig. $5 \mathrm{~b}$ shows the $900^{\circ} \mathrm{C}$. As we can see in Fig. 5 a that the intensity of $\alpha$ phase and $\beta$ phase did not change much when raising the aging temperature of $\alpha / \beta$ solution treated specimens since the $\alpha / \beta$ solution treated specimens contains a large amount of primary a phase and some secondary a phase in $\beta$ matrix. Fig. $5 \mathrm{~b}$ shows the XRD pattern of different aging temperature for the alloy been solution treated at $900^{\circ} \mathrm{C}$. Only the $\beta$ phase can be detected at lower aging temperature $\left(300 \sim 400^{\circ} \mathrm{C}\right)$ by $\mathrm{X}$-ray diffractometer. With the increasing aging temperature, metastable $\beta$ phase decomposed to a phase within the matrix and a phase can only be detected when the aging temperature no less than $450^{\circ} \mathrm{C}$.
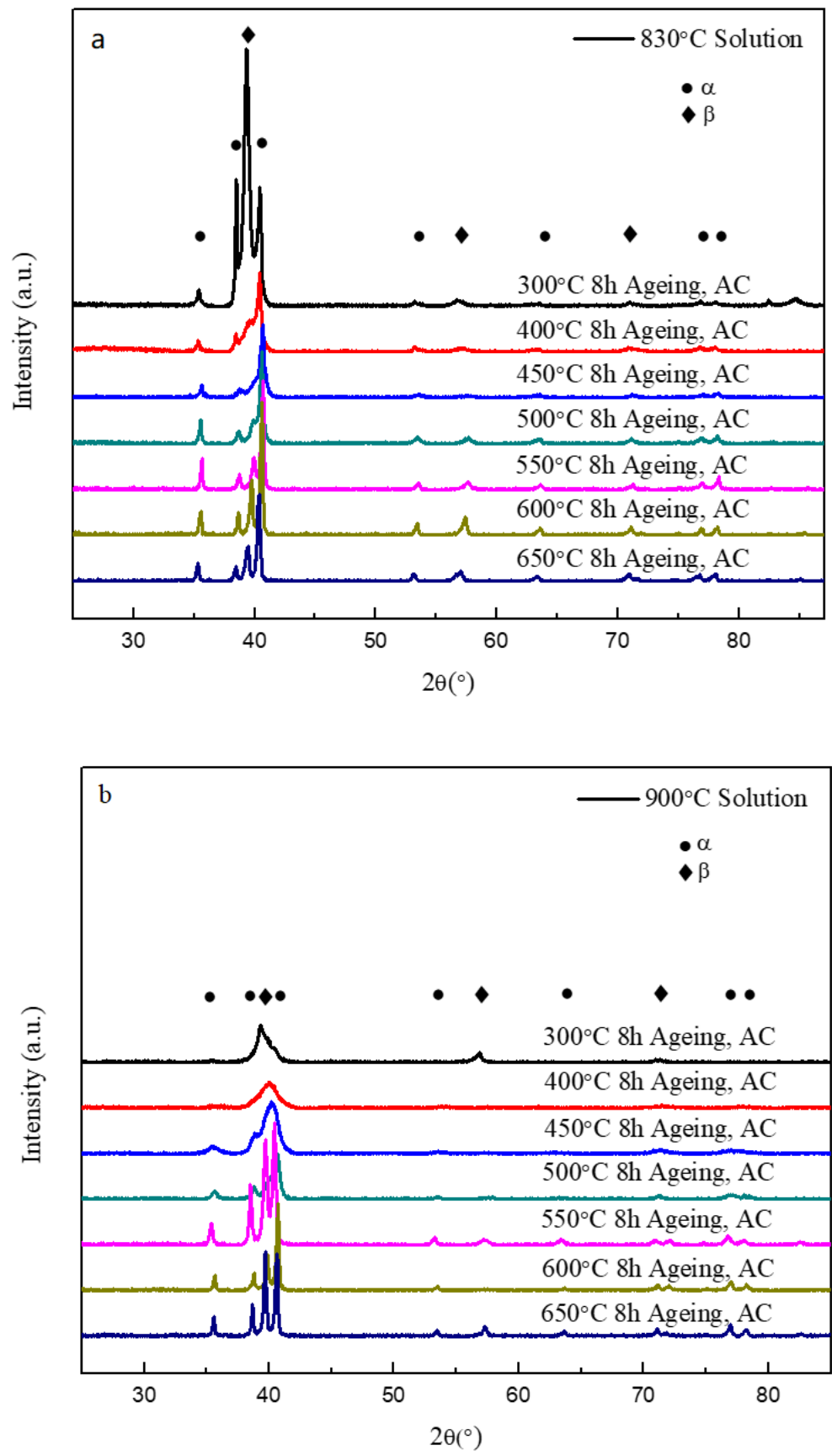

Fig 5. XRD pattern of of Ti-5321 alloy under different aging treated temperature:

a) $830^{\circ} \mathrm{C}$ solution treated specimens, b) $900^{\circ} \mathrm{C}$ solution treated specimens

Fig. 6 shows the TEM bright field images of $450^{\circ} \mathrm{C}$ and $650^{\circ} \mathrm{C}$ aging treated specimens after $\alpha / \beta$ and $\beta$ solution treated. Fine acicular a grains can be found in the $\beta$ matrix in all images. As shown in Fig. $6 \mathrm{a}$ and Fig. $6 \mathrm{~b}$, the average width of the secondary a grains found in the $\beta$ matrix is 20 to $30 \mathrm{~nm}$ when treated at $450^{\circ} \mathrm{C}$ for 8 hours in both solution treated specimens. The grain size grows significantly to 150 to $200 \mathrm{~nm}$ when increase the aging temperature to $650^{\circ} \mathrm{C}$. 


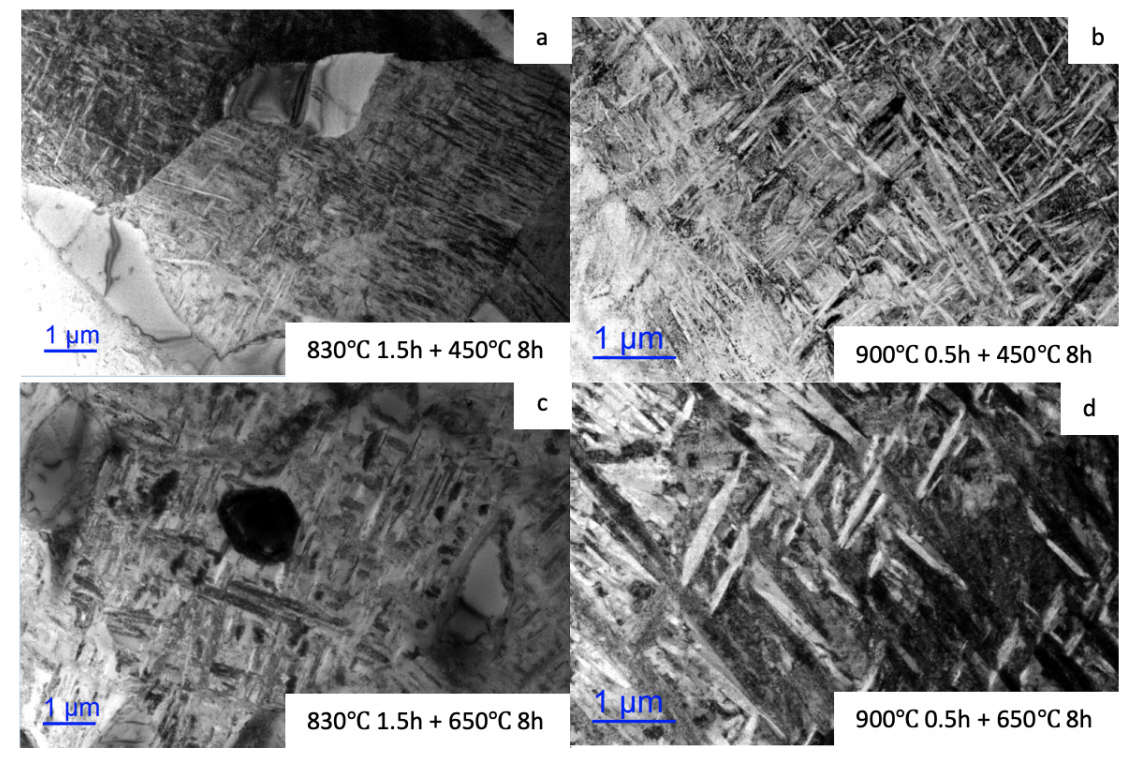

Fig 6. TEM image of different aging temperature treated specimens

\subsection{Mechanical Property}

Fig. 7 shows the tensile strength and elongation of Ti- 5321 alloy performance at room temperature. The best tensile strength is $1564 \mathrm{MPa}$ with $5 \%$ on elongation when Ti5321 treated at $\alpha / \beta$ solution temperature and aged at $450^{\circ} \mathrm{C}$. It is obvious that the solution and aging temperature impact tensile properties significantly for this alloy.

The results also show that the changing rates of tensile strength and elongation of these specimens can be divided into two stages when grouping by solution temperature. For specimens treated under the $\alpha / \beta$ solution temperature, the tensile strength increased and the elongation decreased when specimens aged from $300^{\circ} \mathrm{C}$ to $450^{\circ} \mathrm{C}$ firstly. This phenomenon are mainly caused by the metastable $\beta$ phase transforming to dispersion ultra-fine secondary a phase within the matrix[5, 10]. In the second stage, with continually increasing the aging temperature, the secondary a phase coarsened, and thus cause a lower strength and higher elongation.

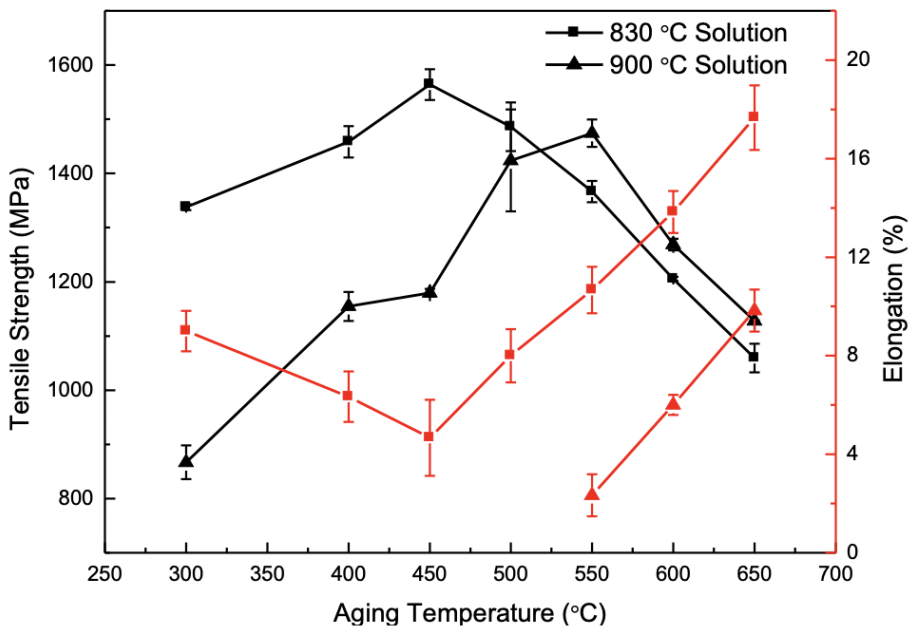

Fig 7. The average value of tensile strength of Ti-5321 after different solution and aging treated temperature

Similar results can also be found in $\beta$ solution treated specimens except that brittle fracture happened when aging at low temperature ( $300^{\circ} \mathrm{C}$ to $500^{\circ} \mathrm{C}$ in this case). It is caused by the existence of extremely fine $\alpha$ phase with width less than $50 \mathrm{~nm}$ along with coarser $\beta$ grain size. The turning point of tensile strength and elongation changing rates can be obtained after $550^{\circ} \mathrm{C}$ aging for this solution temperature. Since the secondary a phase has a higher strength and lower ductility than primary a phase and $\beta$ matrix[9], the ductility for $\alpha / \beta$ solution treatment is better than $\beta$ solution treatments in all aging temperatures.

\section{Conclusions}

In order to investigate the influence of heat treatment on microstructural characteristics and tensile properties of this new near $\beta$ titanium alloy Ti-5321, a comprehensive heat treatment with two solution temperatures (above and below the $\beta$ transus temperature) and a group of aging temperatures were carried out in this study. Following conclusions can be made based on the results:

1. The microstructures and mechanical properties of near $\beta$ titanium like Ti-5321 are sensitive to solution temperature and aging temperature. The highest tensile strength can reach to $1564 \mathrm{MPa}$ with $5 \%$ on elongation when solution treated at $830^{\circ} \mathrm{C}$ for $1.5 \mathrm{~h}$ and aging at $450^{\circ} \mathrm{C}$ for $8 \mathrm{~h}$ for Ti-5321. The best combination of ultimate tensile 
strength and total elongation can reach to $1480 \mathrm{MPa}$ and $8 \%$ simultaneously when solution treated at $830^{\circ} \mathrm{C}$ for $1.5 \mathrm{~h}$ and aged at $500^{\circ} \mathrm{C}$ for $8 \mathrm{~h}$;

2. The metastable $\beta$ phase obtained from $\alpha / \beta$ and $\beta$ solution treated specimens will transform to $a$ phase and disperse within the $\beta$ matrix after lower temperature aging, which improves the mechanical strength effectively. Rapid cooling of $\beta$ solution with low temperature aging treated specimens can brings extremely fine $\alpha$ phase with width less than $50 \mathrm{~nm}$ along with coarser $\beta$ grain size, which contributes to a higher tensile strength and a lower elongation;

3. The primary a phase and dispersed fine secondary a phase can be found in specimens treated under $\alpha / \beta$ solution temperature. The lamellar and globular $a$ grains found in $\alpha / \beta$ solution treated samples contribute to a higher strength by blocking the motion of dislocation and change the propagation of cracks in $\alpha+\beta$ titanium alloys. While, further increasing the aging temperature cause the coarsening of secondary a phase and thus brings up the elongation and brings down the tensile strength simultaneously.

\section{References}

[1] C. Cui, B. Hu, L. Zhao, S. Liu, Materials \& Design, 32 (2011) 1684-1691.

[2] T.W. Duerig, J. Albrecht, D. Richter, P. Fischer, Acta Metallurgica, 30 (1982) 2161-2172.

[3] V.V. Tetyukhin, ITA San Francisco, CA, 1997, pp. 37-54.

[4] S.L. Nyakana, J.C. Fanning, R.R. Boyer, Journal of Materials Engineering and Performance, 14 (2005) 799-811.

[5] N.G. Jones, R.J. Dashwood, M. Jackson, D. Dye, Acta Materialia, 57 (2009) 3830-3839.

[6] Y. Zhao, C. Ma, H. Chang, S. Xin, L. Zhou, Materials China, 35 (2016) 914-918.

[7] L. Ren, W. Xiao, H. Chang, Y. Zhao, C. Ma, L. Zhou, Materials Science and Engineering: A, 711 (2018) 553-561.

[8] Z.Y. Song, Q.Y. Sun, L. Xiao, L. Liu, J. Sun, Materials Science and Engineering: A, 527 (2010) 691-698.

[9] J.W. Lu, Y.Q. Zhao, P. Ge, H.Z. Niu, Y.S. Zhang, W. Zhang, P.X. Zhang, Materials Science and Engineering: A, 621 (2015) 182-189.

[10] O.M. Ivasishin, P.E. Markovsky, Y.V. Matviychuk, S.L. Semiatin, C.H. Ward, S. Fox, Journal of Alloys and Compounds, 457 (2008) $296-309$. 